\title{
Integrated Product, Process and Manufacturing System Development Reference Model: Research Summer as case study
}

\author{
Daniel Cortés, PhD student ${ }^{1}$, José Ramírez, Mechatronics student ${ }^{2}$, Dante Chavarría-Barrientos, PhD, Jhonattan \\ Miranda, $\mathrm{PhD}$ and Arturo Molina, $\mathrm{PhD}^{1}$ \\ ${ }^{1}$ Tecnológico de Monterrey, Mexico City, a01655708@itesm.mx, armolina@itesm.mx \\ ${ }^{2}$ Instituto Tecnológico de Tláhuac, Mexico City, pep_antonio@hotmail.com
}

\begin{abstract}
Open Innovation Laboratory has been developed as an integrated solution that gather all productive stages lifecycle, from ideation to promotion of products. However, every stage of product lifecycle is considered in Integrated Product, Process and Manufacturing System Development (IPPMD) it has been used as Reference Model as approach to reinforce education at higher studies. This Reference Model allows students designing from conceptual ideas to functional prototypes: Products, its manufacturing Process and its Manufacturing System. IPPMD Reference Model (IPPMD-RF) has been integrated in courses of industrial engineering to improve learning process and consolidate previous knowledge related with major. In recent years, this methodology has been extended to Massive Open On-line Courses (MOOCs) and it also has been applied as a technique for those students who forms part of research summer. A case study is shown to demonstrate how this IPPMD as Reference Model works. The results obtained with this Reference Model has proven its usefulness and participants have consolidated multiple area knowledge in different projects.
\end{abstract}

Keywords-Industrial Engineering, Integrated Product, Process and Manufacturing System, Collaborative Learning.

\section{INTRODUCTION}

Nowadays, students are taking advantage of different technologies such as Internet of Things (IoT) and new Information and Communication Technologies (ICT). Consequently, students have become more agile and proactive on their studies and professors acquire the role of information facilitators and leaders of knowledge. In this context, students become more interested in thinking and generating ideas than just following instructions as in standard techniques of education. Technologies are now part of the environment for everybody and students are not exempted. Even these technologies and resources are available, not everybody has access to them and those who do take part on the proposes to provide social, economic and sustainable solutions. ICT and IoT resources can be used to improve and complement traditional education, their main goal is to exchange information and material among classmates and instructors. Thus, scholars and researchers have been developing new learning techniques and methodologies to improve education. In order to integrate multidisciplinary knowledge, improve analytical and critical skills, develop capabilities of observation and decision-making process, forecast different scenarios and get experience in different subjects of their

Digital Object Identifier (DOI): http://dx.doi.org/10.18687/LACCEI2018.1.1.278 ISBN: 978-0-9993443-1-6

ISSN: $2414-6390$ major, Monterrey Institute of Technology and Higher Education, Mexico is developing new spaces provided with tools and technology to foment collaborative learning.

The Integrated Product, Process and Manufacturing System Development Reference Model (IPPMD-RM) is an approach that allows students to decompose product lifecycle into product, process and manufacturing system, however, students are not only encouraged to learn this methodology, but complement it with different approaches in order to elaborate products that respond to economic, social and sustainable problems. IPPMD-RM provides a set of tools to design and develop according to three different entities in four different stages. Thus, learners improve experience and develop different technical and social skills.

This paper aims at demonstrating the use of IPPMD-RM and its set of tools as a technique for implementing active learning in Research summer (students who aim to collaborate in Research projects during summer). At Monterrey Institute of Technology and Higher Education, Mexico this IPPMD$\mathrm{RM}$ has been implemented in Integrated Manufacturing Systems course, there is also a MOOC providing this technique to everybody interested in learning it and Research summer was an opportunity to test this technique with multidisciplinary teams.

Section 2 introduces a review of learning techniques. Afterwards, Section 3 presents the Reference Model, entities, stages and tools applied during each stage. Purpose, Section 4 presents a case study to demonstrate the implementation phase of the IPPMD-RM and tools. Thereupon, conclusions are presented according to Research summer experience.

\section{LEARNING TECHNIQUES}

Active and Collaborative Learning allows multidisciplinary teams to improve their projects and in general, their ideas while developing functional products according to different viewpoints. With the IoT and ICT education have acquired a potential tool to exploit, collaboration [1][2]. Nowadays, students are able to complement ideas and reinforce concepts while collaborating in real time with their classmates.

\section{II.1 Active Learning}

Active Learning (AL) aims at the enrichment of traditional techniques. Students are encouraged to engage with subject, this contrast with traditional methods where lecturers 
transmit plain knowledge. Thus, learners require a vast knowledge in order to accomplish a useful solution [3].

Common strategies that employ AL in educational courses are group discussions, case studies, role plays and projects. The benefits for these techniques, among others, include: improvement in critical thinking skills, improvement of analytical thinking skills, increased retention, reinforcement in concepts, improvement of interpersonal and social skills [4].

$\mathrm{AL}$ has been proven as a useful technique for new generation students, with this, traditional learning techniques does not disappear but complement knowledge acquired by students to face real problems and collaborate with classmates. AL promotes the use of emerging technologies and methods to solve society problems.

\section{II.2 Collaborative Learning}

Collaborative Learning (CL) uses the resources promoted by $\mathrm{AL}$ and aims to create a meaningful project. While $\mathrm{AL}$ promotes the discussion and engagement with subject $\mathrm{CL}$ promotes engagement with a project that has to be developed in team. CL is assembled by active learners and focuses on structured activities; thus, small groups share strength and work up as a team to develop their weaker skills [5].

CL activities improve in learners their understanding of general situations and force them to strategize and improve their individual skills to accomplish a general objective. Although, CL activities are collaborative and aims at a clear objective, individual tasks must be clearly defined and an internal team structure is needed to define tasks, time and resources. Therefore, also leader skills are improved in CL [6].

Learning using $\mathrm{AL}$ and $\mathrm{CL}$ is improved with the inclusion of IoT and ICT rather than conventional techniques. Methods that implement both learning techniques and emerging technologies such as Case-Based Learning, Problem-Based Learning, Project Oriented Learning and MOOCs, produce graduates with improved skills, experiences and knowledge [7].

\section{INTEGRATED PRODUCT, PROCESS AND MANUfACTURING SYSTEM DEVELOPMENT}

IPPMD-RM is a management technique that aims at the development of a products, its manufacturing process and its manufacturing system, it is a methodology formed by Entities, Stages and Tollgates [8]. Also, it is complemented with Smart, Sensing and Sustainable (S) approach [9], and engineering activities.

Due to the fact that it is a Reference Model and it pretends to be a useful guide for every learner, every user needs to adapt it to specific purposes.

For the case study presented further in this document the selected scope of the Product Lifecycle for engineering activities in this research project. The proposed representation has the following attributes as shown in Fig.1:

- Entities are cases to be developed during engineering project: Product Development, Process Development and Manufacturing System.

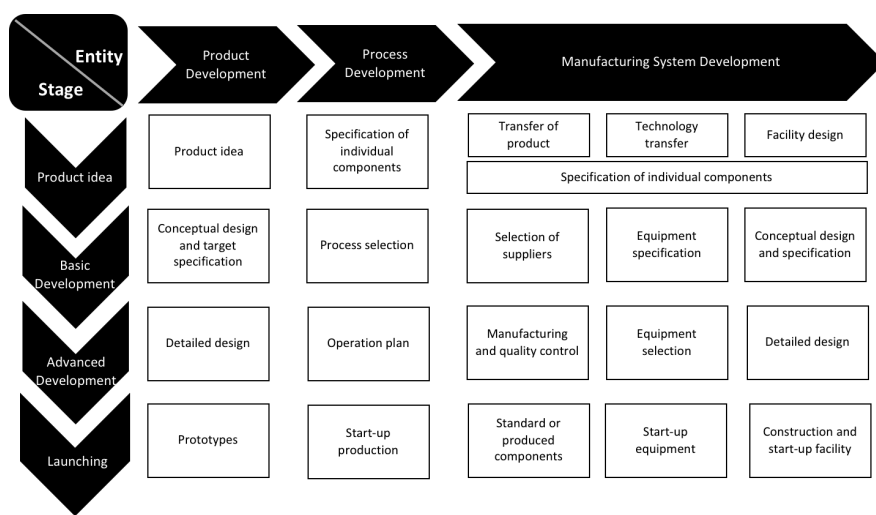

Fig. 1 Integrated Product, Process and Manufacturing System Reference Model.

- Stages are indicator of evolution level for processes: Ideation, Basic Development, Detailed Development and Prototyping.

- Tollgates are concrete results obtained at the end of every stage for a specific entity, e.g. Product Idea is the tollgate for Product Development at Ideation stage.

Open Innovation Laboratory is an integrated solution for every learner interested in accomplish different types of projects. It includes techniques, design methodologies, product realization platforms, artificial intelligence toolkits, decision theatre platform, remote laboratories and recording studios. Open Innovation Laboratory is composed of individual functional laboratories to develop products and projects from Ideation up to Prototyping stages in one building [10]. The goal of both IPPMD-RM and Open Innovation Laboratory is to improve skills taking advantage of AL and CL, providing learners with tools and experiences to accomplish new projects.

Every entity included in the IPPMD-RM is defined at introduction of Research summer for the purpose homogenize knowledge as shown below.

\section{1 Product Development}

Product development process is accomplished at the fourth stage of product lifecycle concept. A set of tools are provided for learners, these are either thinking or technological tools. Also, in every stage activities need to be carried out in order to test the usefulness of the product with potential users, these techniques include analysis, synthesis and evaluation, if there is a problem with the evaluation in one stage, feedback is expected in early stages to correct functionality and design of the product.

In Ideation stage learners can identify innovative and promising products, then, in Basic Development the product is defined with its individual components, therefore, a data sheet conceptualization is expected. Detailed Development stage is where learners assemble their individual components and treat the product as a joint system and finally, Prototyping stage is

16" LACCEI International Multi-Conference for Engineering, Education, and Technology: "Innovation in Education and Inclusion”, 19-21 July 2018, Lima, Peru. 
where a conceptual model evolves to a real functional object and tests are carried out to verify its functions and specifications as shown in Fig. 2.

Tools are provided for learners in order to accomplish their projects as shown in Fig. 3, tools are adapted according to specific needs for learners, these tools include Megatendencies, Benchmarking, Jobs To Be Done, Satisfaction Matrix, Product Lifecycle Management (PLM), Product Data Management (PDM), Computer Aided Design (CAD), Computer Aided Manufacturing (CAM), Computer Aided Engineering (CAE) and different platforms for learners to elaborate prototypes such as 3D printers, Micro factories, Numeric Control (CN), Common Manufacturing equipment.

The tollgates expected during Product Development Entity are functional and beneficial product idea, basic data sheet and different options considered, data sheet with detailed information of suppliers and results of tests and product prototyping.

Activities associated with $\mathrm{S}^{3}$ approach are classified in terms of analysis, synthesis and evaluation. Those are oriented to diagnose, define and prepare information, feedback is expected in every cross between Entity and Stage.

- Analysis activities are oriented to define and prepare different scenarios in order to contemplate multiple solutions.

- Synthesis activities are oriented to combine elements to demonstrate advantages and robustness in different scenarios.

- Evaluation activities are oriented to test solutions and contrast them with goals and requirements.

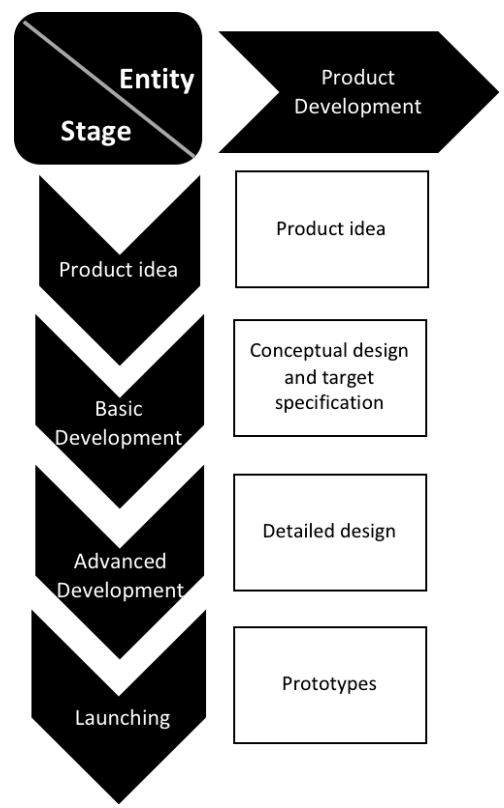

Fig. 2 IPPMD-RM (Partial View $\sim$ Product Development)
Finally, engineering activities are developed in every stage, considering analysis of the function model with expected solutions the user expects from it, synthesis as a summary of the most valuable information to consider in order to acquire individual components, customers, quality and possible process to develop the product and evaluation of product attributes within potential users. This evaluation phase involves the interaction with potential users and feedback is needed in order to develop a functional product.

Additionally, $\mathrm{S}^{\text {s-Product }}$ as reference model allows learners to visualize their product as smart, sensing and sustainable [11]. This enables learners to develop next generation products.

III. 2 Process Development

Process development is the second entity developed by learners. In this phase CL plays an important role, multidisciplinary teams are forced to interact and provide different solutions to accomplish the main objective, also, experience in their area of knowledge provides different ideas according to multiple criteria. Decisions done in process development allow learners to observe repercussions before proceeding to manufacturing system. As shown in Fig. 4 four main stages compose the activities for this entity.

Individual Components Specification allows creation of requirements for each part of the final product. Process Selection is required in order to generate every individual component, even if this is going to be bought and assembled, then, this process is specified and selected by different factors such as cost, availability, supplier. Operations Plan is accomplished when there is specification for inputs and outputs of the process. Finally, Ramp up Production is organized according to schedule, quality control, among others.

\begin{tabular}{|c|c|c|c|}
\hline & Analysis & Synthesis & $\begin{array}{l}\text { Evaluation } \\
\end{array}$ \\
\hline $\begin{array}{l}\text { Product } \\
\text { Ideation }\end{array}$ & $\begin{array}{l}\text { Idea generation } \\
\text { Mogatrends anabsis. } \\
\text { Ethnography and Nenoography. } \\
\text { A day in the life. Empathy map }\end{array}$ & $\begin{array}{l}\text { Understand customer's need } \\
\text { JTBD framowork } \\
\text { Outcome expectations. } \\
\text { Marix of noeds and sariffiers. } \\
\text { KANO, AHP }\end{array}$ & $\begin{array}{l}\text { Product selection } \\
\text { AHP, Pugh chart, Value } \\
\text { proposition, Intellectual propery } \\
\text { analysis, Storyboard }\end{array}$ \\
\hline $\begin{array}{c}\text { Concept } \\
\text { Design and } \\
\text { Target } \\
\text { Specifications }\end{array}$ & $\begin{array}{l}\text { Functional dec omposition } \\
\text { Physical Decomposition, } \\
\text { Functional representation. } \\
\text { Morphological structure. } \\
\text { Sustainable indicator repository }\end{array}$ & $\begin{array}{l}\text { Technical requirements \& } \\
\text { characteristics } \\
\text { QFD } \\
\text { Concept generation } \\
\text { Morphological Marrix, TRIZ }\end{array}$ & $\begin{array}{l}\text { Concept selection } \\
\text { AHP, Pugh chart, LCA, Legal and } \\
\text { Enironmental Regulations }\end{array}$ \\
\hline $\begin{array}{l}\text { Detailed } \\
\text { Design }\end{array}$ & $\begin{array}{l}\text { Modelling and model analysis } \\
P L M(C, A D, C A N, B O M, P D M) \\
\text { (Mechanical, EE and Softurare) }\end{array}$ & $\begin{array}{l}\text { Detailed layout and design } \\
D F M, D F A, D F E, P L M(C A D, \\
\text { CAM, BOM, PDM) } \\
\text { (Mechanical, EE and Softurere) }\end{array}$ & $\begin{array}{l}\text { Modelling and simulation \& } \\
\text { Testing and refinement } \\
\text { PLM (CAE), FME.A, LCA } \\
\text { (Mechanical, EEE and Software) }\end{array}$ \\
\hline Prototyping & $\begin{array}{l}\text { Prototype derelopment and } \\
\text { fabrication } \\
\text { Rapid prototping (RP). } \\
\text { By parts, } \\
\text { Virtual protoope (VP). } \\
\text { Functional protooppe (FP) } \\
\text { (Mechanical, EE and Software) }\end{array}$ & $\begin{array}{l}\text { Prototype development and } \\
\text { fabrication } \\
\text { Rapid protonping, Integration, } \\
\text { Virnal prototype, } \\
\text { Functional protonpe } \\
\text { (Mechanical, EE End Software) }\end{array}$ & $\begin{array}{l}\text { Prototype testing } \\
\text { FMEA, Usability testing on } \\
\text { consumer and users }\end{array}$ \\
\hline
\end{tabular}

Fig. 3 IPPMD-RM Toolbox

16 ${ }^{\text {th }}$ LACCEI International Multi-Conference for Engineering, Education, and Technology: "Innovation in Education and Inclusion", 19-21 July 2018, Lima, Peru. 


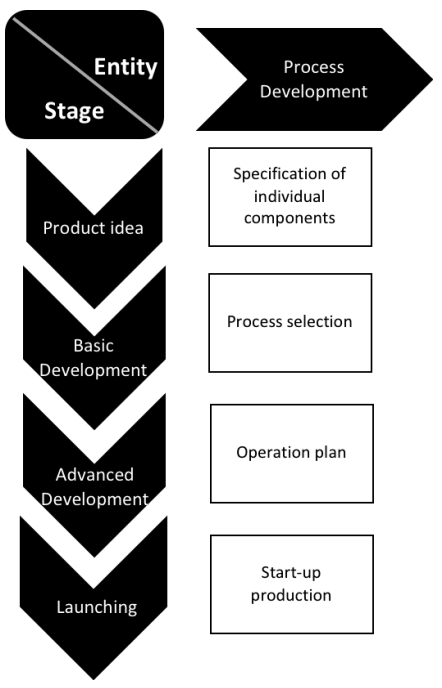

Fig. 4 IPPMD-RM (Partial View $\sim$ Process Development)

For process development, different tools and techniques are provided to learners, OPITZ classification system, Value Stream Mapping VSM, CAD, CAE, CAM, among others. Feedback of the product provides restrictions for process development as well as manufacturing system, however, physical properties of the product is a starting point to discard processes among the variety it exists [12][13].

\section{III.3 Manufacturing System Development}

Manufacturing system development considers three sub processes that define how a company manufactures the product and its individual parts as shown in Fig. 4.

- Product Transfer: if the component is a standard part of a conventional manufacturing process, supplier is found and fulfill requirements about cost, time and quality.

- Technology Transfer: if a traditional process must manufacture the component, supplier is not found but technology is available in the market or in the company.

- Facility Design: if the component needed is not standard and the technology is not available in the market, then, it is necessary to develop a new machine to produce individual components.

Depending on the necessities identified in Product and Process Development entities, Ideation of the manufacturing system is provided. For product transfer, suppliers are selected, quality controls are established, and components are manufactured and assembled. For technology transfer, equipment specifications are defined, suppliers are selected, and equipment is installed and prepared. For machine design, the stages followed include conceptual design, detail design, construction and setup.

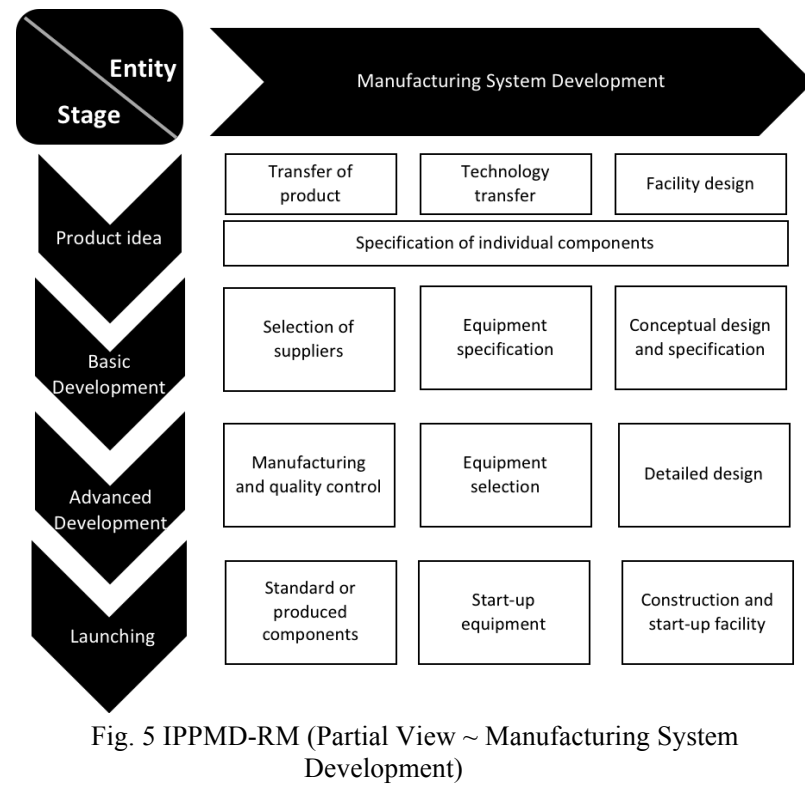

Manufacturing System Development has been improved with enterprise concerns. S3 reference model approach is instantiated to generate the enterprise model. With this, all information is managed and monitored providing useful data for enterprise stakeholders. This approach is expected in enterprises who aims Industry 4.0 [14].

Enterprise Viewpoint instantiates objectives of the company and business concepts. Tools are provided to learners in order to acquire a general idea of the business that emerges from product, its manufacturing process and its manufacturing system, the main tool used is Canvas model. Information detailed from Canvas model aids decision making for suppliers, interaction between potential users and learners provides feedback and Enterprise Viewpoint is consolidated with all interactions needed to accomplish the product lifecycle. Information Viewpoint serves as a repository of the information to take all the decisions. Computation Viewpoint, captures the enterprise behavior by doing business process modelling. Engineering viewpoint establishes the required services, applications and technologies for implementation of the business processes. Technology Viewpoint contemplates the specification of technology needed, providers, suppliers, distribution, among others [15].

Five Viewpoints align human, machines and application to communicate in the same language [16].

\section{CASE Study: Research SUMmer}

The most recent case study was conducted by students of the "XXIII Verano de la Investigación Científica y Tecnológica del Pacífico 2017". During their stance, the students were involved in activities in which they used specific learning techniques, design methodologies and rapid product realization platforms. The use of all these resources results in an experience that goes from the conceptualization of an idea to

16" LACCEI International Multi-Conference for Engineering, Education, and Technology: "Innovation in Education and Inclusion”, 19-21 July 2018, Lima, Peru. 
the practical manifestation of it in a totally organized way that allows obtaining promising results for the innovative ideas that can contribute to the specific assigned projects. A crucial part of these experiences relies in the implementation of concepts such as $\mathrm{S}$ reference model, IPPMD-RM, MOOC under Coursera platform called "Desarrollo Rápido de Productos Inovadores para Mercados Emergentes" and physical tools like the makers spaces installed in the institution.

During this stance, the students were asked to contribute with their ideas to implement improvements on a specific research topic in which the research team was currently working on. The process began with the presentation of the project that in this occasion was a reconfigurable micromachine capable of performing different computerized machining tasks and that has the purpose of serve as a tool in different manufacturing areas that goes from educational institutions, small and medium enterprises (SME) and private use in emerging economies where it is necessary to provide solutions at low cost with good quality. Open Innovation Laboratory is an integrated solution for learners interested on creating projects and developing integral solutions where $\mathrm{S}^{3}$ approach is presented to learners and different solutions were proposed referring to sensing, smart and sustainable solutions as shown in Fig. 6. Sensing was conceptualized during stance as a series of sensors capable of measuring sound, vibration and electric current, sensing was conceptualized as integrated components to enable IoT in micro-machine and sustainable was identified as the way to dispose the components at the end of its useful life.

First of all, a detailed description of features and capabilities of the machine is done, then the students make extensive use of it to identify key issues in design or functionality. After a detailed analysis of their experience, several improvements that could be applied on it are made. Once the proposals have been identified, the students make use of different tools, methodologies and learning techniques that allow them to refine the idea and finish with an innovative concept that depending on the complexity of the idea can be physically implemented or will lay the foundations for future research. The four proposals that are in-depth studied are: the implementation of laser engraver and 3D printing, an app designed for the micro-machine and finally the inclusion of IoT for remote management of it.

The organization method consists on forming interdisciplinary teams to achieve the greatest variety in the contribution of ideas, however everybody can contribute with their knowledge at a given time. For this research stance, five teams of two members were formed and each one was assigned to the development of a specific proposal. In this case of study, the task of the fifth team that was responsible for conducting a thorough Research on the possibility of adapting the machine to perform food printing is excluded because it was only handled conceptually. During research development, a continuous feedback is done to clarify doubts and weekly progress review is made to propose corrections and ideas that could mean improvements in the development of their idea.

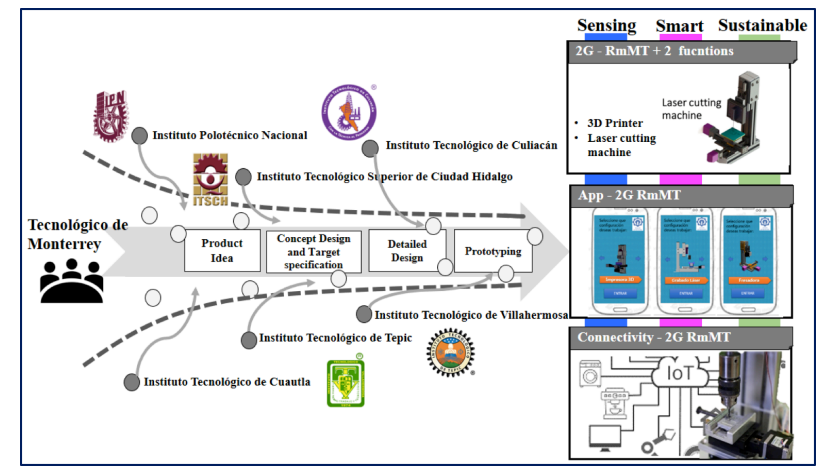

Fig. 6 Open Innovation for learners using IPPMD-RM

To implement the laser, a detailed study was made of the technological options available for cutting and engraving functions. These vary in power, useful life, capabilities, difficulty of implementation and safety. However, the challenge for the students was the adaptation of the technology to the scale of the micro-machine. For this, different analysis of individual parts of the micro-machine were made taking into account that little to none modification would be necessary to adapt the chosen module. Making extensive use of the various tools in the IPPMD toolbox it was possible to reduce the number of permutations until eventually the laser diode stood as the best option to minimize impact on original design. A similar process was carried out to implement the 3D functionality in the micro-machine. In this case there were already sketches and there was equipment corresponding to extruders, hot plates, thread reels and various elements needed to $3 \mathrm{D}$ print. As in the case of the laser, it was a matter of reducing impact on the original design provided with the micro-machine. This required from electronic control design tasks to manufacture of mechanical elements. The two teams working on the expansion of mechanical functions of the micro-machine agreed that a future work to be done is the implementation of a numerical control that allows the same flexibility of software morphing as the physical side.

Another team proposed the remote management of the micro-machine using IoT elements which through various types of sensors can monitor and manage through a Wi-Fi network its operation. The original concept proposed by the students consists of 3 main blocks: sensors, data acquisition and transmission-reception of information. Here we make use of the concepts provided by the S3 reference model that involve Sensing by means of all the sensors applied to parameter measuring during the machining of parts, Smart that includes all the management of the information obtained by the sensors to make an holistic approach that monitor in real time the status of the machine and Sustainable to efficiently manage resources like raw materials and energy to reduce the environmental impact. It should be noted that the methodology allowed to detect that the different operating systems propose a design challenge since each one requires a specific programming so a more efficient way to coexist between this variety of software was the implementation of a more universal system based on HTML to be displayed in a web browser. 
The case of the app designed for the micro-machine shows the importance of the methodologies used to propose innovative ideas. During ideation stage it was possible to identify areas of opportunity that might not be obvious. From the proposals studied above, it can be identified that they focus principally in the technical aspect of the machine intuiting that the user already has notions of manufacturing systems. However, it leaves aside those interested in entering the world of computerized manufacturing. With this idea, this team of students concentrated on making a compendium of practices that evolve from the basics to more advanced notions applied to each of the configurations of the machine. Within the app you can find concepts of machining operations, a guide to the most used $\mathrm{G}$ codes and examples of parts with their respective codes.

To summarize results, a tool called decision theatre was used in which each team was able to show in a versatile way all the findings during the summer stance. For all scenarios, a collaborative and interdisciplinary environment was required in which all students contributed with ideas and knowledge to solve problems. The learning techniques proposed in this summer stance like the blended learning, the problem based learning along with the specific methodologies aided by a complete set of manufacturing techniques provided by the maker spaces allowed the students to contribute significantly to the research topic of the reconfigurable micro-machine.

\section{CONCLUSION}

Presented work shows the methodological use of the Integrated Product, Process and Manufacturing System Development Reference Model to support Active and Collaborative Learning in Research summer. Thus, the IPPMD reference model provided systematized activities to be carried out during learning process, tools and tollgates to provide learners with a complete guide to develop Products, Process and Manufacturing Systems.

This reference model allows learners to have both active and collaborative learning processes during the Research summer. Technologies used promote the analytical and critical thinking in a collaborative environment. The paper presented a case study, where the IPPMD reference model was applied to different projects at Tecnologico de Monterrey promoted by Programa Delfin. Results show that the students can propose products, manufacturing process, manufacturing systems and enterprise business models in a systematized and holistic way during a period of time shorter than two months, emphasizing sustainable practices.

The implementation of the reference model allows demonstrating that using this reference model in combination with new learning methods and emergent technologies enable the development of learner's skills and capacities. However, future work is required to design an assessment program to evaluate student's performance in each competency. Therefore, the impact level of this implementation proposal can be measured, future works would be center on this objective.

\section{ACKNOWLEDGMENT}

This research has been funded by the NOVUS 2016 2017 program by Tecnologico de Monterrey as part of the project entitled "Sensing, Smart and Sustainable Makerspace for the design of Innovative Products"; 'Connected Communities' Initiative by the Seed Grant form CITRIS as part of the project "S3-Microfactory (Sensing, Smart and Sustainable) to support the maker movement"; funded by CONACYT as part of student scholarships and Programa Delfin "For Researching Culture".

\section{REFERENCES}

[1] Maksimovic, M. (2017). IOT CONCEPT APPLICATION IN EDUCATIONAL SECTOR USING COLLABORATION (Vol. 1).

[2] Shoikova, E., Nikolov, R., \& Kovatcheva, E. (2018). SMART DIGITAL EDUCATION ENHANCED BY AR AND IOT DATA.

[3] Vacek, P., \& Rybenska, K. (2015). Research of Interest in ICT Education among Seniors. Procedia - Social and Behavioral Sciences, 171, 10381045. doi:https://doi.org/10.1016/j.sbspro.2015.01.276

[4] Pereira-Santos, D., Prudêncio, R. B. C., \& de Carvalho, A. C. P. L. F. (2017). Empirical Research of active learning strategies. Neurocomputing. doi:https://doi.org/10.1016/j.neucom.2017.05.105

[5] Pan, C., Li, J., Wang, Y., \& Gao, X. (2018). Collaborative learning for hyperspectral image classification. Neurocomputing, 275, 2512-2524. doi:https://doi.org/10.1016/j.neucom.2017.11.035

[6] Sarwar, B., Zulfiqar, S., Aziz, S., \& Ejaz Chandia, K. (2018). Usage of Social Media Tools for Collaborative Learning: The Effect on Learning Success With the Moderating Role of Cyberbullying.

[7] P. Dillenbourg, M. J. Baker, A. Blaye, C. O'Malley. The evolution of research on collaborative learning. Spada, E. and Reiman, P. Learning in Humans and Machine: Towards an interdisciplinary learning science., Elsevier, Oxford, pp.189-211, 1995.

[8] Arturo Molina Gutierrez, 2012, "Modelo de referencia para configurar/reconfigurar el desarrollo integral de producto, proceso y sistema de manufactura", in Spanish, presented at Academia Mexicana de Ingeniería, 19/1/2012, http://www.ai.org.mx/miembros/273

[9] Chavarría-Barrientos, D., Batres, R., Wright, P. K., \& Molina, A. (2017). A methodology to create a sensing, smart and sustainable manufacturing enterprise. International Journal of Production Research, 1-20. doi:10.1080/00207543.2017.1386333

[10]J. Miranda, D. Chavarría-Barrientos, M. Ramírez-Cadena, M. E. Macías, P. Ponce, J. Noguez, R. Pérez-Rodríguez, P. K. Wright, A. Molina. "Open Innovation Laboratory for Rapid Realization of Sensing, Smart and Sustainable Products (S3 Products) for Higher Education.” International Journal of Social, Behavioral, Educational, Economic, Business and Industrial Engineering Vol:11, No:5, 2017.

[11]Miranda, J., Pérez-Rodríguez, R., Borja, V., Wright, P. K., \& Molina, A. (2017). Sensing, smart and sustainable product development (S3 product) reference framework. International Journal of Production Research, 122. doi:10.1080/00207543.2017.1401237

[12]A. Vasile, I. Kiss, and S. Ratiu. "Management of classification and coding systems used in group technology-based production processes." Annals of the Faculty of Engineering Hunedoara 12.42014.

[13]S. Tyagi, A. Choudhary, X. Cai and K. Yang. "Value stream mapping to reduce the lead-time of a product development process". International Journal of Production Economics, 160, pp. 202-212. 2015

[14]Leyh, C., Martin, S., \& Schäffer, T. (2018). Analyzing Industry 4.0 Models with Focus on Lean Production Aspects.

[15]D. Chavarria-Barrientos, R. Batres, R. Perez, P. K. Wright, and A. Molina. "A Step Towards Customized Product Realization: Methodology for Sensing, Smart and Sustainable Enterprise." In Working Conference on Virtual Enterprises, pp. 327-339. Springer International Publishing. October 2016.

G. Weichhart, A. Molina, D. Chen, L. E. Whitman, and F. Vernadat. Challenges and current developments for sensing, smart and sustainable enterprise systems. Computers in Industry, 79, pp. 34-46. 2016

16" LACCEI International Multi-Conference for Engineering, Education, and Technology: "Innovation in Education and Inclusion", 19-21 July 2018, Lima, Peru. 